\title{
How the Tivaevae Model can be Used as an Indigenous Methodology in Cook Islands Education Settings
}

\author{
Aue Te Ava ${ }^{1}$ and Angela Page ${ }^{2}$ \\ ${ }^{1}$ College of Indigenous Studies, Education and Research, University of Southern Queensland, Toowoomba 4350, Queensland, \\ Australia \\ ${ }^{2}$ School of Education, University of New England, Armidale 2351, New South Wales, Australia
}

\begin{abstract}
This paper explores an Indigenous research methodology, the tivaevae model, and its application within the Cook Islands education system. The article will argue that the cultural values embedded within its framework allow for the successful implementation of this Indigenous methodology. The model draws from tivaevae, or artistic quilting, and is both an applique process and a product of the Cook Islands. It is unique to the Cook Islands and plays an important part in the lives of Cook Islanders. The tivaevae model will be explained in detail, describing how patchwork creative pieces come together to create a story and can be used as a metaphor of the past, present and future integration of social, historical, spiritual, religious, economic and political representations of Cook Island culture. Further, the paper will then make links with the model to teaching and learning, by exploring secondary schools' health and physical education policy and practices. Finally, the efficacy of the model in this context and its research implications will then be discussed.
\end{abstract}

- Keywords: culturally responsive pedagogy, tivaevae model, Indigenous research methodologies, Cook Islands cultural values, education

For more than a decade, Pacific Indigenous research methodology has been promoted as an alternative paradigm for research that involves Indigenous people's issues (Airini, Anae, \& Mila-Schaaf, 2010; Anae, 2007; Otu'nuku, 2011). Pacific research refers to Indigenous research methodology as 'the production of Indigenous knowledge [that] helps construct conditions that allow for Indigenous self-sufficiency while learning from the vast storehouse of Indigenous knowledge that provide compelling insights into all domains of human endeavour' (Kincheloe \& Steinberg, 2008, p. 12). In challenging traditional western ways of knowing and researching, Smith (1999) called for both the decolonization of methodologies and a new agenda for Indigenous research. These methodologies complement developments of research in the Cook Islands education context, making space for Indigenous concepts such as tapu (the sacred) and vaerua ora (the spiritually uplifting) to emerge in research practices. In this way, new research practices and understanding of knowledge become apparent. Kincheloe and Steinberg (2008) showed how research might focus on Indigenous people's unique attributes and the relevance of cultural values and rituals in their own right. Jonassen
(2003) reiterated that Indigenous knowledge also refers to the cultural values and stories that Cook Islands Elders contribute to research, and how this ensures credibility and reliability. As Smith (1999) argued, decolonisation in research is concerned with having 'a more critical understanding of the underlying assumptions, motivations and cultural values that inform research practices' (p. 214). Understanding and valuing multiple assumptions, motivations and cultural values is an important part of research that can allow the creation of opportunities for Indigenous people researching about their own people. The aim of this paper is to explore how the tivaevae model can be used as an Indigenous methodology in Cook Islands education research. The findings show that the tivaevae model was able to guide research that sought to explore a cultural pedagogy that was expressed within Cook Islands education. The research was conducted in three phases that describe various patterns and protocols of the values

ADDRESS FOR CORRESPONDENCE: Aue Te Ava, College of Indigenous Studies, Education and Research, University of Southern Queensland, Toowoomba 4350, Queensland, Australia.

Email: ateava572@gmail.com 
and beliefs that are interwoven into educational pedagogy. The paper further explains the contributing processes of the tivaevae model as a culturally responsive methodology and how this links to a way forward for research within Cook Islands education.

Salmond (1983) argued that western research brings with it a particular set of values and conceptualizations of time, space, subjectivity, gender relations and knowledge. Colonial (western) power continues to evolve and to marginalise Indigenous groups (Wilson, 2001; Wood, 2006). Building on these themes, Smith (1999) commented that Indigenous research needs to consider how the Indigenous 'worldviews' may (re)inscribe the dominant discourse of what counts as knowledge. An appreciation of Indigenous epistemology holds transformative possibilities for research, in general, and Pacific research, in particular.

As Indigenous models for research are becoming valued in education, Pacific research methods in education have been developing and considered as culturally appropriate research methods (Airini, Anae, \& Mila-Schaaf, 2010; Health Research Council, 2004; Mara, 2008; MauaHodges, 2003; Sasau \& Sue, 1993; Thaman, 2003; Samu \& Siteine, 2006). Although western research paradigms have influenced Pasifika communities in various projects, Anae, Anderson, Benseman and Coxon (2002) argued that the goal for Pacific research must be to 'identify and promote a Pacific world view' (p. 12). Significantly, Anae (2007) suggested that research should be 'owned, driven and directed by Pacific peoples' (p. 13). Advantages of Pacific research include the integration of advanced knowledge of cultural values and language relevant to the research, and the way these values are distributed and produced in networking and protocols (Airini, Anae, \& Mila-Schaaf, 2010).

Pacific values are integral to Pacific education research. Some researchers suggest that Pacific research approaches should have values expressed within an appropriate philosophical framework, such as Sanga and Niroa (2004), who argued that 'Indigenous Pacific research is based on a philosophy of human nature' (p. 42). They proposed that 'Pacific researchers develop Pacific research within their own philosophical orientation' (p. 42), because this is how Pacific research credibility is determined. For Sanga and Niroa (2004), research on or by Pacific people must use 'strategies that are Pacific in nature' (p. 48). Similarly, Lima (2004) invited researchers to identify ways that Pacific knowledge and values might best be integrated into research values and practices that were meaningful to Pacific people.

Models of Pacific research methodology, many intentionally ethnic specific, have been developed (Tamasese, Peteru, Waldegrave, \& Bush, 2005). With a particular concern for Pacific research in the health sector, Tamasese, Peteru, Waldegrave and Bush (2005) argued that the development of Pacific-specific research methodologies would avoid 'the danger of Western interpretation and enable an authentic Pacific-based approach through an exploration of the experiences of Cook Islands people and the meanings they construct around critical mental health issues and definitions' (p. 301). Further, the authors stated that the purpose of Pacific research was to provide a rigorous research method that would be 'relevant and acceptable in a Pacific context' (p. 301). From a Tongan perspective, Thaman (2003) drew on the practice of making kakala as a culturally appropriate approach to research. She proposed that the three key processes involved in the making of kakala are as follows: the toil (gathering of the kakala), tui (the making or weaving of the kakala) and luva (the giving away of the kakala). These processes, she suggested, were congruent to local research. These approaches to research show that, as a whole, Pacific research methodologies embrace existing Pacific values of respect, cultural competency, meaningful engagement and reciprocity (Anae, Coxon, Mara, Wendt-Samu, \& Finau, 2001; Health Research Council, 2004).

\section{The Cook Islands Context}

The Cook Islands is located in the South Pacific Ocean in free association with New Zealand. It comprises 15 islands whose total land mass is 240 square kilometres ( 92.7 square miles); however, the Cook Islands covers 1,800,000 square kilometres (690.000 square miles) of ocean. The resident population of the Cook Islands is 14,974 thousand people (Ministry of Finance \& Economic Management, 2012). Cook Islands education research follows a western research framework and fails to take into account Cook Islands values and cultural identity. This notion is supported by the work of Te Ava, Airini and Rubie-Davies (2011), illustrating how Cook Islanders maintains the levels of success, and that new ways of attaining knowledge are needed through education research.

In the Cook Islands context, there is also relevance to the development of a framework that is responsive to Cook Islands education research, and Maua-Hodges (2003) has contributed to such a framework in early childhood which reflects connections to Cook Islands cultural practices and values by developing the tivaevae model. In this paper, we have used this model to demonstrate education research in Cook Islands setting. The values reflected in the tivaevae model were used to research a culturally responsive pedagogy in the Cook Islands (Te Ava, Rubie-Davies, Airini, \& Ovens, 2013). With these goals in mind, this paper proposes a research methodology drawn from Cook Islands knowledge, values and practices of the tivaevae. The tivaevae model draws from various aspects of the study such as planning (first phase), sewing of the patterns of the tivaevae together (second phase) and reflecting the outcome of the tivaevae (third phase). Of particular interest, the relationship between the tivaevae model and a culturally responsive pedagogy will be demonstrated. Further, the relevance to research and education policy in the 
Cook Islands context will be highlighted. In this paper, we explore the significance of the tivaevae model in three phases of the study that mirrors the three phases of tivaevae making. By drawing on the comparisons of the tivaevae process in order to illustrate its application to educational research, the paper presents the findings of research with physical education (PE) teachers who explain the underpinning processes of using the tivaevae model in teaching culturally responsive pedagogy.

\section{The Tivaevae}

The tivaevae model is based on the tivaevae, a canvas decorated with an array of cloth of different designs and patterns with the aim of making a picture or telling a story. Many early Europeans showed interest in the tivaevae when visiting the Cook Islands and report it to be an intricate and fascinating process (Crocombe \& Crocombe, 2003). Rongokea (2001) explained that there are two basic methods of sewing a tivaevae: patchwork or piecework, and appliqué. Further, there are four different styles: tivaevae Taorei (piecework/patchwork), tivaevae Manu (appliqué), tivaevae Tataura (appliqué and embroidery) and tivaevae Tuitui Tataura (embroidered squares of fabric joined together with either crocheting or lace borders). Tivaevae is sewn by women and supported by the men in preparation of activities such as funerals, weddings, twenty-first birthdays, traditional hair cutting and graduation.

The tivaevae reflects how culturally responsive practice conveys teaching and learning of Cook Island daily practices. It depicts the past, present and future and how these values are integral to the social, cultural, historical, spiritual and religious, economic and political representation of Cook Island culture. The tivaevae patterns have many meanings and inspire how Cook Islands people function in their environment (Rongokea, 2001). The tivaevae also mirrors how the various Cook Island communities collectively come together to help one another to develop and grow into a better nation (Sissons, 1999).

The making of the tivaevae also represents the teaching and learning of our papa'anga (genealogy) and knowledge. Papa'anga refers to the genealogy of the family unit whose knowledge of the past is handed down from generation to generation. The sharing of knowledge has been handed down by our ui-tupuna (ancestors) throughout the centuries and constituted a valuable educational process. The wisdom of the past was transferred through cultural practices such as songs, music, arts and crafts, chants, legends and karioi (traditional dance). The metua tane and metua vaine (elders and higher authorities) recognise that the more people involved in the teaching and learning process, the more Cook Islanders understand their cultural heritage and ui-tupuna (ancestors) (Rongokea, 2001). Inasmuch as teaching and learning is conveyed within the community, for these reasons, the tivaevae remains a very important social phenomenon.

\section{Tivaevae as an Indigenous Research Methodology}

The tivaevae model (Maua-Hodges, 2003) was the key theoretical framework that underpinned this research. It provided a holistic model which could be used to guide the multiple components of research in culturally responsive ways. Just as the pieces of the tivaevae create a collective whole, research using the tivaevae model could likewise explore secondary schools' health and physical education (PE) policy and practices. The similarities were considered to be useful in supporting teachers to better plan and evaluate their own levels of culturally responsive pedagogy.

The application of the tivaevae as a research model was hoped to centre Cook Islands people's understanding of values as has been the case when other Indigenous research methods have been employed (Wilson, 2001). Smith (1997) argued that by placing Indigenous paradigms and people at the centre, research methodology practices and outcomes are better situated meaningfully to " $[c]$ ontinually speak to the people ... in ways which the people understand . . . It must keep meaning alive. It must have meaning to the people in terms of their lived reality. Praxis must involve the people reflecting on their reality' (p. 164). For New Zealand Māori, these practices have been interpreted as language integration, knowledge and culture concerns on the one hand with economic, political and social (e.g. education, health and justice) concerns on the other. Such intentions are envisaged as an important part of education research in the Cook Islands.

With a view to supporting educational achievement in the Cook Islands, three key dimensions of tivaevae making were embedded in Maua-Hodges tivaevae research model: koikoi, tuitui and akairianga. The koikoi referred to the gathering of the patterns needed for the making of the tivaevae (Maua-Hodges, 2003). Patterns were picked and readied for discussion before being sewn together. The koikoi process required knowledge and experience in planning, gathering the appropriate materials at the right time and at the right place and ensuring that the pattern tells a story of Cook Islands history. These stories are tapu (sacred), central to the values of Cook Islands cultural practice and made ready for crafting into a tivaevae. The significance of this phase is that Cook Islanders learn to create their own way of understanding of the world in which they live. They, in effect, bring their own knowledge and investigate how the 'patterns' fit together and then are evaluated for success. In this research, the 'patterns' represented the experiences of the teachers, students and pa metua (Elders) shared with each other. The nature, degree, direction, pathway, place and time were circumspectly determined by the participants in their immediate 
surroundings, and shaped by their world views. This was a dynamic interaction of storytelling, debating, reflecting and sharing knowledge of genealogies, along with food and other necessities. Again, the tivaevae model was chosen because it underpins Cook Islands culture and is appreciated within and across the relationships of the pa metua, schools, teachers and students.

The second aspect of the tivaevae model is tuitui, the sewing or stitching of the pattern on the blank canvas. Tuitui refers to the actual making of the tivaevae. This process requires special knowledge and skills of different types of 'patterns' depending on the occasion or the individual who would be using the tivaevae for decoration. A further key aspect of the tivaevae model is making connections. When Cook Islanders come together during tuitui to make the tivaevae, they made connections with each other and began developing relationships. Both English and Te reo Maori Kuki Airani were also significant where relationships are progressively established as well as acquaintances shared. It was the development of friendship and relationship was a crucial component for the tuitui part of tivaevae because the strength of those relationships, positions and connections determines the beauty and complexity of the finished tivaevae. Thus, in terms of research and the relationships which were part of the study, the degree of honesty and transparency in sharing information, opinion and attitudes was well identified. Making connections and developing relationships with the PE teachers and the school over a period of time were therefore an important part of the study design.

The final aspect is akairianga. This is the evaluating and offering of the tivaevae to the community or to individuals as a gift. In the Cook Islands culture, the tivaevae represents a symbolical token of two Cook Islands values, aroa (love) and tu akangateitei (respect). Once the tivaevae is completed, it is blessed for the special occasion.

The benefit of the symbolic pattern in tivaevae making integrating Cook Islands culture into the education research ensures valuable meaning to be realised. Educational research in the Cook Islands is thus perfectly positioned to explore Cook Islands theories of knowledge in practice. Further, tivaevae making supports a range of cognitive, physical, cultural, interpersonal (social) and intrapersonal (emotional, moral, aesthetic and spiritual) aspects and lends itself well to the PE curriculum framework. How the methodology was applied across the three phases is described in the following section.

\section{Incorporating the Tivaevae Model in the Research}

The main reason for using the tivaevae model as a research process was its establishment of validity and acceptance among Cook Islanders. Aligned with the tivaevae process, the research study exploring culturally responsive pedagogy was conducted in three phases:
- Phase one (preparing a tivaevae pedagogical model)

- Phase two (sewing the tivaevae patterns together)

- Phase three (reflecting on the tivaevae - student perceptions)

\section{Phase One - Preparing a Tivaevae Pedagogical Model}

The study elicited a new research approach based on the values identified in Phase one. Pa metua were interviewed and agreement was sought regarding the values of taueue, angaanga taokotai, akatano, angaanga oire kapiti, te reo Maori Kuki Airani and auora that were needed in PE classes as they were an important part of the tivaevae process. According to interviews with the teachers involved, such changes to content, structure, language and context in lesson plans should accommodate students' engagement and alertness to their responsibility toward learning; moreover, these amendments should explicitly emphasise Cook Islands values which identified students within cultural contexts.

\section{Phase Two - Sewing the Tivaevae Patterns Together}

After the process of embedding Cook Islands values in PE teaching planning (Phase one), the teachers found the task of implementing these new approaches (Phase two) challenging. Teachers reported difficulties in improvising lessons as it provided a very different perspective to learning. The teachers, however, were motivated and received encouragement and practical advice to support the integration of cultural knowledge within their PE contexts. In turn, students in Phase two reported the Cook Islands relevant $\mathrm{PE}$ activities rewarding, in terms of enjoyment and expanded knowledge. However, others indicated they did not enjoy the experience because it was traditional and focused on cultural activities. The question remained, however, of how students perceived the relative merits of teaching infused with Cook Islands activities and values compared with those based on western models and content.

Additionally in Phase two, teachers experienced improvements in their teaching skills in terms of culturally responsive practices and students became more independently responsible for their own learning. This created a significantly different learning environment. Subsequently, the emphasis on the Cook Islands values in teaching not only increased teachers' confidence in being culturally responsive, but also enabled students to take up leadership roles and to participate in more positive ways. Developing competence in implementing a culturally responsive pedagogy in the Cook Islands PE curriculum was evident as a result of the study. This was an important outcome from using the tivaevae methodology. Teachers, for example, acquired a basic knowledge of Cook Islands culture and language and were able to utilise 
these and associated values within teaching and learning contexts. The recommendation of the values initiated in the tivaevae model led to the implementation of changes to the Cook Islands PE curriculum for the first time. Consequently, teachers took ownership of these values and enacted them within curriculum documents and policy frameworks through partnership with communities and other Pasifika educators.

\section{Phase Three - Reflecting on the Tivaevae - Student Perceptions}

In Phase three, reflections are made on the outcome of the implementation of the tivaevae process. The results indicated that overall, PE was important to students. A qualitative analyses capture students' feelings for the family, cultural and personal factors relating to PE in schools. They showed that overall, students valued the inclusion of cultural activities within PE less than they valued traditional forms of PE and much less than they perceived that their families valued PE. It was suggested that the students were not used to the inclusion of traditional activities and values in the PE programme and so preferred what they were used to, that is, western forms of PE. It should be remembered, however, that of the students who placed less value on the inclusion of cultural activities, the majority saw these activities as enhancing their experience of PE. Further, students only experienced four lessons that included cultural activities, and so were this to become more common place, it is likely that student positivity towards the inclusion of cultural activities in physical education would increase.

Phase three provides a fresh insight into how the inclusion of cultural activities is interconnected with student learning, given that academic education traditionally has a higher priority. The results indicate the implications for students pertaining to future pedagogy in schools. Cultural activities provide students with an opportunity to explore their social and cultural needs, a balance which is not merely limited to addressing the academic needs of students within the school environment. Phase three also concerned creating wellbeing within learning in a manner that is more inclusive. The core values which the students perceive for physical education teaching and learning in an environment that represents continuity in students' development of cultural as well as academic understanding were created and maintained. The inclusion of culture in learning is a reflection of a student's culture and identity and as such could become an important factor in students' achievement in school.

\section{Research Implications of the Tivaevae Model}

The following discussion briefly describes why the tivaevae model has significant implications for Cook Islands research. Core values for teaching contribute to the tivae- vae model from discussions with the pa metua. This was important because it showed links between the Elderselders, the model and the teaching. At the initial meeting with the participants, there were opportunities for introductions and reflection of past experiences which had impacted the development of health and physical education in the schools. Discussions regarding the purposes of the research were always open and negotiable. There were many opportunities for questions, through individual discussions, and then together, through a collaborative planning process towards the actual investigation and collecting of research data.

The tivaevae model was shown that it can be used as a relevant framework when doing research with Cook Island participants. This has been realised by the Cook Islands Ministry of Education that applied the process in the development of a new school being built in Rarotonga (Davies, 2015). The challenge for Cook Islands researchers was to prioritise the use of research frameworks that could be used within a holistic perception of knowledge and scholarship, appropriate communication styles both oral and written and which endorse the protocols of consensus and respect.

The tivaevae model can benefit Cook Islands education research through bringing together cultural communities, scholars, researchers and students to engage in the critique of the research and knowledge production process. The tivaevae model also provides an opportunity to engage in the cultural traditions of the Indigenous/Cook Islands knowledge by sharing lived experiences and retaining their authority and ownership of that knowledge (Te Ava, Airini, \& Rubie-Davies, 2011). Bringing research methodologies and practices in line with the priorities of Cook Islands peoples is a new effort to identify and address barriers in research.

\section{Relationship of the Findings to the Tivaevae Model}

The research outlined in this article contributed to the tivaevae model by developing a set of values which supported students in their learning. This provided greater relevance as a culturally responsive pedagogy. These values form the flower pattern that is part of the tivaevae. Samu, Mara, and Siteine (2008) argued that developing the $t u$ ingangaro (trust and academic achievement) is one of the many keys in Pasifika education where knowledge between teacher and student was gradually constructed. To support this argument, a culturally responsive pedagogy is recommended for schools to develop strong relative foundations of knowledge establishment between teacher and student.

Peu puapinga is the values pattern that acknowledges culturally responsive pedagogy. As a consequence, the potential to become the corner stone for students' learning, as identified by the pa metua, these consistent values 
become clear. These values include the following: tāueue (participation), angaanga taokotai (cooperation), akatano (discipline), tu akakoromaki (patience), ngakau akaaka (humility), tu kauraro (obedience or obey), angaanga oire kapiti (community involvement), te reo Maori Kuki Airani (Cook Islands Maori language) and auora (physical and spiritual wellbeing). From an Indigenous Canadian perspective, Sackney and Walker (2006) identified the centrality of values of respect and honour, similar to those encapsulated in the Cook Islands value of peu puapinga. This was supported by Ama (2003), who stated that Cook Islands peu puapinga are essential for the development of a healthy society and an enriching environment that prepared a challenging pathway for Cook Islands youth to achieve goals and objectives in schooling. These values were all reflected in the thoughts of the pa metua as important to schooling and wider social practices and were incorporated into the tivaevae model that arose from the findings of the research.

The pattern flower akaputuputuanga taokotai was representative of a value identified as central to culturally responsive pedagogy: respect and support for peers. Akaputuputuanga taokotai means learning from each student and developing students' confidence as they work together with their teachers in cultivating student's talents through vaerua ora (spirit). Jonassen (2003) argued that akaputuputuanga taokotai was an element of tu tangata meaning personality and culture. Accordingly, tu tangata was kite pakari (wisdom) and aroa (love) are significant to the student learning environment. Of note, having teachers as the main source of delivery deliberately encouraged and inspired students to become versed in their peu oraanga (cultural identity). The involvement of parents and communities in this learning process was found to persuade students to akaputuputuanga taokotai. Moreover, different generations gain opportunities to develop the abilities to mentor each other. Values are important for culturally responsive pedagogy and need to be embedded within the research design to allow for a culturally appropriate methodology to occur. Additionally, the principles of kauraro (respect), tu inangaro (reciprocity), ngutuare tangata or anau (family), vaka tangata oire (community experts), putuputuanga vaine tini e te tane tini (women and men's community projects), taokotai (cooperation), and kopu tangata (community workers) need to be considered and incorporated.

\section{Conclusion}

Pasifika research models like the tivaevae outline the appropriateness of cultural appropriate methodology in research. The intention and responsibility of Pasifika researchers is to continue to address cultural issues and add to its collective wisdom. In order to systematically reveal the cultural knowledge and social construction of cultural identity within the discipline of applied research, the tivae- vae was used as a methodological research model in underpinning culturally responsive pedagogy that embraces the values of the Cook Islands. The tivaevae model offered a new approach in research where Cook Islands culture, language and relationships based on akangateitei (respect), aroa or inangaro (love) and tauturu (service) bring meaning to both the researcher and participants. The tivaevae model highlighted the challenges of Cook Islands research and how this is processed and written within a Cook Islands context. This provided an open space and comfortable platform for establishing reciprocal engagement through dialogue and telling stories, and sharing of cultural and spiritual experiences, throughout the research.

\section{References}

Airini, A., Anae, M., \& Mila-Schaaf, K. (2010). Teu le vaRelationships across research and policy in Pasifika education: A collective approach to knowledge generation and policy development for action towards Pasifika education success. Wellington, New Zealand: Ministry of Education.

Ama, A. (2003). Maeva: Rites of passage, the highlights of family life. In R. Crocombe \& M. Crocombe (Eds.), Akanoanga Maori: Cook Islands culture (pp. 119-126). Suva, Fiji: University of the South Pacific.

Anae, M. (2007). Teu le va: Research that could make a difference to Pasifika schooling in New Zealand. Paper commissioned by the Ministry of Education and presented at the joint NZARE/Ministry of Education symposium, 'Is your research making a difference to Pasifika education?' Wellington.

Anae, M., Anderson, C., Benseman, J., \& Coxon, E. (2002). Pacific peoples and tertiary education: Issues of participation. Wellington: Ministry of Education.

Anae, M., Coxon, E., Mara, D., Wendt-Samu, T., \& Finau, C. (2001). Pasifika education research guidelines. Wellington: Ministry of Education.

Crocombe, R., \& Crocombe, M. (Eds.) (2003). Akano'anga Maori: Cook Islands culture. Suva, Fiji: University of the South Pacific.

Davies, A. (2015). How to make it stick: Pedagogy and MLEs. In K. Cheval \& A. Duncan (Eds.), Korero: The Research journal for cook islands educators (Vol. 3, pp. 63-70). Rarotonga, Cook Islands: Cook Islands Ministry of Education.

Health Research Council. (2004). Guidelines for Pacific health research. Wellington: Health Research Council of New Zealand.

Jonassen, J. (2003). Tu tangata: Personality and culture. In R. Crocombe \& M. Crocombe (Eds.), Akano'anga Maori: Cook Islands. Suva, Fiji: University of the South Pacific.

Kincheloe, J.L., \& Steinberg, S.R. (2008). Indigenous knowledges in education: Complexities, dangers, and profound benefits. In N. Denzin, Y. Lincoln, \& L.T. Smith, (Eds.), SAGE handbook of qualitative research, the handbook of critical and indigenous methodologies (4th ed.). Thousand Oaks, CA: Sage Publications. 
Lima, I. (2004). Tafesilafa'i: Exploring Samoan alcohol use and health within the framework of a Fa'asamoa. Doctoral thesis, The University of Auckland. Retrieved June 10, 2009 from https://researchspace.auckland.ac.nz/bitstream/handle/ 2292/2171/02whole.pdf? sequence $=3$

Mara, D. (2008). Invisible knowledge, virtual journeys and real communities: Pacific communities and information. Keynote address presented at the 2008 Conference of the Library and Information Association of New Zealand Aotearoa, Auckland, New Zealand.

Maua-Hodges, T. (2003). Tivaevae. Unpublished manuscript. Retrieved June 10, 2009 from http://www.justice.govt.nz/pubs/reports/2003/ pacificvictims/pacificpeoplesvictimsofcrime

Ministry of Finance and Economic Management Cook Islands (2012). Census of Population and Dwellings, 2011. Retrieved from http://www.mfem.gov.ck/ images/documents/Statistics_Docs/5.Census-Surveys/ 4.Census-Report/2011_Cook_Islands_Population_ Census_Report.pdf

Otu'nuku, M. (2011). How can talanoa be used effectively as an Indigenous research methodology with Tongan people? Journal of Pacific-Asia Education, 23(2), 43-52.

Rongokea, L. (2001). The art of tivaevae: Traditional Cook Islands quilting. Auckland: Gowit.

Sackney, L., \& Walker, K. (2006). Canadian perspectives on beginning principals: Their role in building capacity for learning communities. Journal of Educational Administration, 44, 341-358.

Salmond, A. (1983). The study of traditional Maori society: The state of the art. Journal of Polynesian Society, 92, 309331.

Samu, T.W., Mara, D., \& Siteine, A. (2008). Education for Pacific peoples for the 21 st century. In V. Carpenter, J. Jesson, P. Roberts \& M. Stephenson (Eds.), Nga Kaupapa Here: Connections and contradictions in education (pp. 145-157). Melbourne: Cengage.

Samu, T.W., \& Siteine, A. (2006). The social studies teachers Pasifika awareness programme. Paper presented at the International Assembly of Social Studies Teachers, Washington DC, USA.

Sanga, K. \& Niroa, J. (2004). First steps and small beginnings in Vanuatu education research. In K. Sanga, J. Niroa,
K. Matai, \& L. Crowl (Eds.), Re-thinking Vanuatu education together (pp. 12-21). Port Vila: Ministry of Education, and University of the South Pacific, Institute of Education.

Sasau, T. \& Sue, S. (1993). Toward a culturally anchored ecological framework of research in ethnic cultural communities. American Journal of Community Psychology, 21, 705-727.

Sissons, J. (1999). Nations and destination creating Cook Islands identity. Cook Islands: Institute of Pacific Studies and the University of the South Pacific Centre.

Smith, G.H. (1997). Kaupapa Maori as transformative praxis. Unpublished doctoral thesis, The University of Auckland.

Smith, L.T. (1999). Decolonising methodologies: Research and Indigenous peoples. Dunedin: University of Otago Press.

Tamasese, K., Peteru, C., Waldegrave, C., \& Bush, A. (2005). Ole Taeao Afua, the new morning: A qualitative investigation into Samoan perspectives on mental health and culturally appropriate services. Australian and New Zealand Journal of Psychiatry, 39, 300-309.

Te Ava, A. (2001). The role of physical education in preserving traditional sports and games in the Cook Islands: Units of instructions. Unpublished Master's thesis submitted to the Department of Kiniesiology and Leisure Science at the College of Education, University of Hawai'i at Manoa.

Te Ava, A., Airini, A., \& Rubie-Davies, C. (2011). Akarakara Akaouanga i te Kite Pakari O Te Kuki Airani: Culturally responsive pedagogy. Journal of Pacific-Asia Education, 23(2), 117-128.

Te Ava, A., Rubie-Davies, C., Airini., \& Ovens, A. (2013). Akaoraoraia te Peu 'A To 'Ui Tupuna: Implementing Cook Islands core values in culturally responsive pedagogy in Cook Islands physical education classrooms. Australia Indigenous Research Education Journal, 42(1), 32-43.

Thaman, H.K. (2003). Decolonising Pacific studies: Indigenous perspectives knowledge, and wisdom in higher education. The Contemporary Pacific, 15, 190-191.

Wilson, C. (2001). Decolonizing methodologies: Research and Indigenous peoples. Social Policy Journal of New Zealand, 17, 214-217.

Wood, H. (2006). Three competing research perspectives for Oceania. Contemporary Pacific, 18, 33-55.

\section{About the Authors}

Aue Te Ava is a Lecturer in educational technology, instructional design, and adult education. He holds a Doctor of Philosophy $(\mathrm{PhD})$ focused on health and physical education from the University of Auckland.

Angela Page is originally from New Zealand and has worked as an Inclusive Education advisor to schools and governments in the Pacific region as well as lecturing in inclusive education and classroom management. She has a particular interest in the development of inclusive and special education practices for students with disabilities within new or emerging contexts. 